\title{
Assessment of salinity intrusion in coastal districts of Ben Tre province using Landsat 8 image
}

\author{
Lam N. Le ${ }^{1 *}$, Trung V. Le $e^{2}$ \& Thinh V. Tran ${ }^{3}$
}

*Faculty of Land Management and Real Estate, Nong Lam University, Ho Chi Minh City, Vietnam

${ }^{2}$ Faculty of Environment and Natural Resources, Ho Chi Minh City University of Technology, Ho Chi Minh City, Vietnam

${ }^{3}$ Faculty of Agronomy, Nong Lam University, Ho Chi Minh City, Vietnam

ARTICLE INFO
Research Paper
Received: June 01, 2020
Revised: July 30,2020
Accepted: August 21, 2020
Keywords
Climate change
Electrical conductivity (EC)
Landsat 8 OLI
Salinity
Remote sensing
*Corresponding author
Le Ngoc Lam
Email: lengoclam@hcmuaf.edu.vn

\section{ABSTRACT}

Monitoring and evaluation of saline water intrusion is an important task, especially for agricultural production in Ben Tre province. The paper introduces a new solution in the application of Landsat 8 satellite imagery and field survey data to determine the soil electrical conductivity (EC) for soil salinity assessment through the distribution of EC indice value. Analyzing and establishing the correlation between reflectance value, salinity indices and EC allow selecting a suitable model for the creation of a soil salinity map in 4 levels corresponding to EC values: no salinity $(0-4)$, mild $(4-8)$, moderate $(8-16)$, very salinity $(>16)$. Research results in 2019 showed that most of the coastal districts of Ben Tre province were salty with EC values ranging from 8 to 16 . The salinity decreased gradually from the East Sea to the mainland with the distance from 15 to $25 \mathrm{~km}$. In brief, the study proposed solutions for rapid monitoring and evaluation of soil salinity based on the easy access of Landsat 8 images to calculate the necessary indices in the establishment of soil salinity maps for the local and regional scale.

Cited as: Le, L. N., Le, T. V., \& Tran, T. V. (2020). Assessment of salinity intrusion in coastal districts of Ben Tre province using Landsat 8 image. The Journal of Agriculture and Development $19(4), 45-55$. 


\title{
Ứng dụng ảnh Landsat 8 đánh giá xâm nhập mặn các huyện ven biển thuộc tỉnh Bến Tre
}

\author{
Lê Ngọc Lãm ${ }^{1 *}$, Lê Văn Trung ${ }^{2} \&$ Trần Văn Thịnh ${ }^{3}$ \\ ${ }^{1}$ Khoa Quản Lý Đất Đai và Bất Động Sản, Trường Đại Học Nông Lâm TP.HCM, TP. Hồ Chí Minh \\ ${ }^{2}$ Khoa Môi Trường và Tài Nguyên, Đại Học Bách Khoa TP.HCM, TP. Hồ Chí Minh \\ ${ }^{3}$ Khoa Nông Học, Trường Đại Học Nông Lâm TP.HCM, TP. Hồ Chí Minh
}

\section{THÔNG TIN BÀI BÁO}

Bài báo khoa học

Ngày nhận: 01/06/2020

Ngày chỉnh sửa: $30 / 07 / 2020$

Ngày chấp nhận: 21/08/2020

Từ khóa

Biến đổi khí hậu

Độ dẫn điện (EC)

Landsat 8 OLI

Nhiễm mặn

Viễn thám

*Tác giả liên hệ

Lê Ngọc Lãm

Email: lengoclam@hcmuaf.edu.vn

\section{TÓM TẮT}

Giám sát và đánh giá xâm nhập mặn là nhiệm vụ quan trọng, đặc biệt đối với sản xuất nông nghiệp trên địa bàn tỉnh Bến Tre. Bài báo giới thiệu giải pháp mới trong ứng dụng ảnh vệ tinh Landsat 8 và dữ liệu điều tra thực địa để xác định độ dẫn điện của đất (electrical conductivity - EC) nhằm đánh giá nhiễm mặn trong đất thông qua sự phân bố của EC. Phân tích thiết lập sự tương quan giữa giá trị phản xạ và các chỉ số độ mặn với $\mathrm{EC}$ cho phép chọn mô hình phù hợp trong thành lập bản đồ độ mặn của đất theo 4 cấp độ tương ứng với giá trị EC: không nhiễm mặn $(0-4)$, nhẹ $(4-8)$, vừa $(8-$ 16), rất mặn (>16). Kết quả nghiên cứu năm 2019 cho thấy hầu hết các huyện Thạnh Phú, Ba Tri và Bình Đại đều bị nhiễm mặn với giá trị $\mathrm{EC}$ từ $8-16$. Độ mặn giảm dần theo hướng từ biển đông vào đất liền với khoảng cách từ 15 đến $25 \mathrm{~km}$. Tóm lại, nghiên cứu đã đề xuất các giải pháp trong giám sát và đánh giá nhanh nhiễm mặn trong đất dựa trên khả năng truy cập dễ dàng của ảnh Landsat 8 để tính các chỉ số cần thiết trong thành lập bản đồ độ mặn đất cho cấp vùng và cấp khu vực.

\section{1. Đặt Vấn Đề}

Cùng với hiện tượng nước biển dâng, xâm nhập mặn là một trong những hậu quả nghiêm trọng nhất của biến đổi khí hậu, ảnh hưởng đáng kể đến các hoạt động nông nghiệp và sinh kế người dân ở nhiều nơi trên thế giới, đặc biệt là khu vực ven biển. Hiện tượng này ngày càng trở nên nghiêm trọng và thường xuyên xảy ra ở đồng bằng sông Cửu Long của Việt Nam, là một trong những nước chịu tác động mạnh bởi biến đổi khí hậu. Trong đó, Bến Tre với chiều dài $65 \mathrm{~km}$ tiếp giáp Biển Đông và có hệ thống sông ngòi chằng chit, trên $90 \%$ diện tích đất có cao độ địa hình từ 1-2 m so mực nước biển, nên nhiều vùng thấp ven sông, biển thường xuyên bị ngập khi triều cường. Do đặc thù điều kiện tự nhiên, Bến Tre được nhận định là một trong những tỉnh bị ảnh hưởng nặng nề của biến đổi khí hậu và nước biển dâng đặc biệt là xâm nhập mặn.

Đất nhiễm mặn từ quan điểm nông nghiệp, là đất đó có tồn tại các loại muối hòa tan ở một nồng độ cao hơn bình thường, gây ảnh hưởng xấu đến cây trồng. Ở những vùng ven biển, đất thường dễ bị mặn hoặc nhiễm mặn thông qua các cơ chế trong tự nhiên như triều cường, nước ngầm thẩm thấu, hoặc do tác nhân thông qua quá trình sử dụng đất như làm muối, nuôi trồng thủy sản. Như vậy, để xây dựng một hệ thống phân loại xâm nhập mặn nói chung và đất nhiễm mặn nói riêng trên cơ sở tích hợp dữ liệu diều tra với tư liệu viễn thám đòi hỏi có những nghiên cứu, kiểm chứng thực địa cụ thể.

Hiện nay, dữ liệu viễn thám đã được sử dụng ngày càng nhiều trong các nghiên cứu về độ mặn của đất, do khả năng cung cấp thông tin nhanh hơn và hữu ích trong việc đưa ra dự đoán thực tế (Shrestha, 2006). Ngoài ra, ảnh vệ tinh đa thời 
gian còn cho phép xác định sự thay đổi độ mặn ở quy mô khu vực, cũng như việc kết hợp các chỉ số thực vật như chỉ số thực vật tăng cường (Enhanced Vegetation Index - EVI) và các chỉ số độ mặn (Salinity Index - SI) tạo khả năng đánh giá xu hướng độ mặn của đất trong thảm thực vật và đất trống tương ứng do độ nhạy cảm với các đặc điểm muối (Widad \& ctv., 2018). Ủu thế của việc ứng dụng ảnh Landsat đã được minh chứng trong nghiên cứu đánh giá việc phát hiện các sự cố tràn nước muối ở Hạt Bottineau, Bắc Dakota, Ấn Độ. Trong đó, chỉ số độ mặn phản ứng Canopy (Canopy Response Salinity Index CRSI) được trích xuất từ các kênh hồng ngoại và hồng ngoại nhiệt của ảnh Landsat (Neha, 2019).

$\mathrm{Xu}$ thế mới trong khai thác ảnh Landsat- 8 với dữ liệu cảm biến Operative Land Imager (OLI) để giám sát và thành lập bản đồ độ mặn của đất phân bố theo không gian dựa trên các chỉ số độ mặn của đất (Soil Salinity Index - SSI) đã minh chứng tính hiệu quả của giải pháp. Trong đó, hồi quy tuyến tính đa biến (Multi Linear Regression - MLR) đã được áp dụng để xác định mối tương quan giữa các giá trị phản xạ phổ và số liệu của các phép đo mặt đất về độ dẫn điện (electrical conductivity - EC) để đánh giá độ mặn của đất. Kết quả cho thấy mối tương quan cao giữa SSI và EC để dự đoán độ mặn của đất (Watheq \& ctv., 2018). Một nghiên cứu khác được thực hiện ở khu vực Garmsar Plain ở phía Đông của Tehran, với 288 mẫu đất được phân tích để xác định mối quan hệ giữa độ phản xạ phổ và độ dẫn điện $\mathrm{EC}$ như là chỉ số độ mặn. Phân tích hồi quy được sử dụng để kiểm tra mối quan hệ giữa $\mathrm{EC}$ và các chỉ số độ mặn để tạo ra một số mô hình (Ali \& ctv., 2012).

Nhìn chung, ảnh Landsat 8 OLI được sử dụng khá phổ biến để tính toán các chỉ số đánh giá độ mặn của đất bao gồm: Chỉ số độ mặn đất thực vật (Vegetation Soil Salinity Index - VSSI), chỉ số thực vật có hiệu chỉnh phản xạ mặt đất (Soil Ajusted Vegetation Index - SAVI), chỉ số thực vật chuẩn hóa (Normalize Difference Vegetation Index - NDVI) và chỉ số khác biệt độ mặn đất (Normalize Difference Salinity Index - NDSI). Trong đó, nhiều kết quả chỉ ra rằng, giá trị phổ của dải cận hồng ngoại (Near Infra Red - NIR) và VSSI có mối tương quan cao với $\mathrm{EC}(\mathrm{r}=0,7779$ và $\mathrm{r}$ $=0,6957$, tương ứng) so với các chỉ số khác. Kết quả so sánh cũng cho thấy độ mặn của đất được giải đoán từ ảnh Landsat 8 khá phù hợp với dữ liệu thực tế. Các nghiên cứu này đã minh chứng việc sử dụng ảnh Landsat 8 OLI có khả năng ứng dụng cao trong việc giám sát không gian độ mặn của lớp đất trên cùng khu vực (Nguyen \& ctv., 2020).

Từ các nghiên cứu trên cho thấy việc ứng dụng ảnh viễn thám trong đánh giá độ mặn đất EC thường sử dụng phân tích hồi quy để xác định mối tương quan giữa $\mathrm{EC}$ với chỉ số phát triển thực vật NDVI, chỉ số thực vật có hiệu chỉnh phản xạ mặt đất SAVI và nhóm chỉ số độ mặn đất bao gồm: chỉ số độ mặn SI (Salinity Index) từ 1 đến 7 , chỉ số khác biệt độ mặn đất NDSI, chỉ số độ mặn đất thực vật VSSI, chỉ số tỷ lệ mặn SR (Salinity Ratio), chỉ số độ mặn và độ mặn đất SSSI. Tuy nhiên, phương pháp thu thập dữ liệu thực địa và độ chính xác phân tích mẫu là các yếu tố ảnh hưởng trực tiếp đến độ chính xác mô hình hồi quy giữa giá trị phản xạ phổ của ảnh Landsat với giá trị EC để tính toán chỉ số độ mặn. Bài báo giới thiệu kết quả thử nghiệm việc trích xuất các thông tin từ bộ cảm biến OLI của ảnh Landsat 8 để tính toán độ mặn đất thông qua chỉ số dẫn điện trong đất (EC), từ đó thành lập bản đồ độ mặn của đất phân bố theo không gian khu vực các huyện duyên hải của tỉnh Bến tre.

\section{Vật Liệu và Phương Pháp Nghiên Cứu}

\subsection{Vật liệu}

Ảnh Landsat: Ảnh vệ tinh Landsat có 8 bands với độ phân giải từ $15-60 \mathrm{~m}$ ghi lại phản xạ của các đối tượng có bước sóng từ vùng nhìn thấy $(0,4$ đến $0,7 \mu \mathrm{m})$ đến vùng hồng ngoại nhiệt $(12,5 \mu \mathrm{m})$ được ứng dụng trong nhiều lĩnh vực nghiên cứu. Vệ tinh thế hệ thứ 8 - Landsat 8 đã được Mỹ phóng thành công lên quỹ đạo vào ngày 11/02/2013 với tên gọi gốc Landsat Data Continuity Mission (LDCM). Landsat sẽ tiếp tục cung cấp các ảnh có độ phân giải trung bình (từ 15 $100 \mathrm{~m})$.

Bản đồ chuyên đề: bao gồm bản đồ hành chính tỉnh Bến Tre, Bản đồ hiện trạng sử dụng đất tỷ lệ $1 / 25.000$ thành lập năm 2019, được biên tập và xử lý trên phần mềm Mapinfo 12.0 cùng hệ tọa độ với ảnh Landsat 8 OLI và cắt theo ranh giới vùng nghiên cứu là ba huyện $\mathrm{Ba}$ Tri, Bình Đại và Thạnh Phú để phục vụ cho việc chồng xếp kiểm tra đánh giá kết quả. Ngoài ra, bản đồ chuyên đề còn được sử dụng để thành lập bản đồ phân bố điểm mẫu với các thông tin thuộc tính như Tọa độ X,Y, mã khoanh đất, giá trị EC. 


\subsection{Phương pháp nghiên cứu}

Xử lý ảnh và phân tích hồi quy là hai phương pháp chính được sử dụng trong nghiên cứu. Trong đó, việc thu thập dữ liệu thực địa của 28 điểm mẫu (Hình 1) được lấy trong thời gian từ 15/01/2019 đến 20/01/2019 bằng thiết bị đo cảm ứng điện tử EM31-MK2. Khi đo ngoài thực địa các thông số nhiệt độ, độ ẩm được cài đặt đồng bộ. Các điểm mẫu sau đó được nội suy xử lý đồng bộ các đặc điểm môi trường và tổng quát hóa về tầng dày mặt đất với độ sâu trong khoảng từ 0 - $20 \mathrm{~cm}$. Các điểm mẫu sau đó được đánh giá và khảo sát tương quan giữa giá trị độ mặn đất (EC) với các giá trị phản xạ kênh phổ (từ kênh 2 dến kênh 5 ảnh Landsat 8 OLI). Các chỉ số độ mặn đất sau khi được chiết tính từ ảnh Landsat sẽ được sử dụng trong xây dựng mô hình hồi quy phù hợp nhất, để thành lập bản đồ độ mặn đất (EC) cho khu vực nghiên cứu.

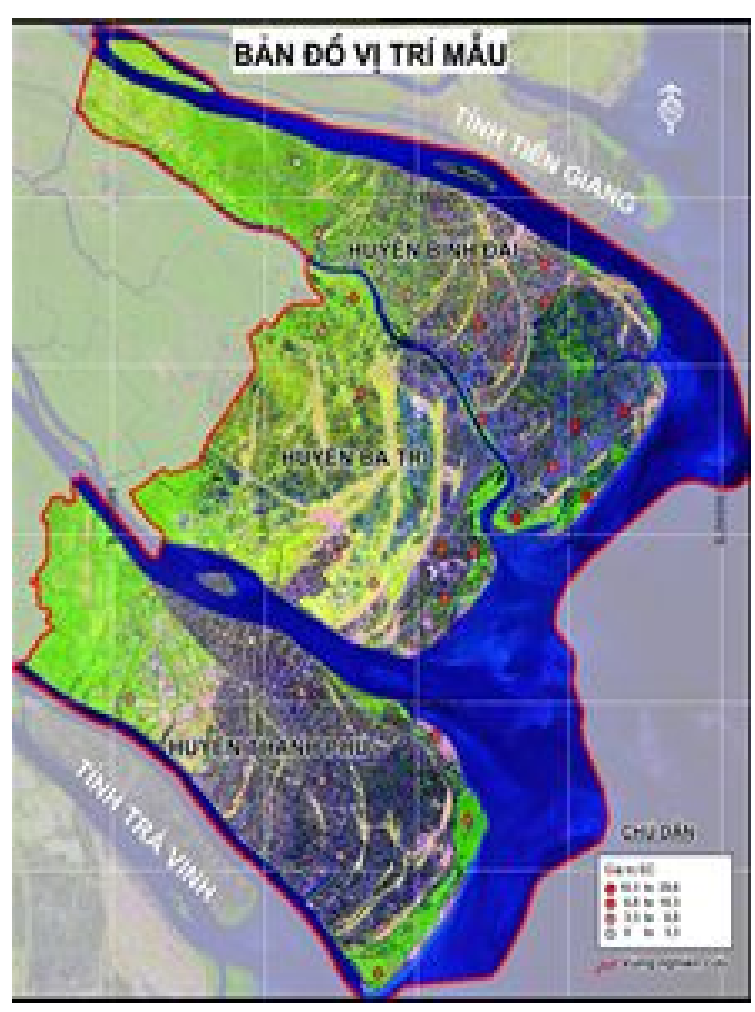

Hình 1. Sơ đồ vị trí điểm mẫu.

Giá trị phản xạ (Reflectance value) các kênh ảnh Landsat 8 OLI được sử dụng để trích xuất các chỉ số độ mặn: SAVI, NDSI, VSSI, SI1, SI2, SI3, SI4, SI5 dựa theo công thức cho ở Bảng 1. Trong đó, red, green, blue là các giá trị tương ứng kênh khả kiến $(2,3,4)$ và NIR (Near Infra Red) là giá trị tương ứng kênh hồng ngoại gần (kênh 5).

Các điểm mẫu sau khi được phân tích để xác định giá trị EC tiến hành phân tích tương quan với các chỉ số độ mặn được trích xuất từ ảnh vệ tinh Landsat 8 OLI. Kết quả hồi quy từ 28 điểm mẫu được sử dụng để chạy mô hình lan truyền mặn theo giá trị EC để thành lập bản đồ xâm nhập mặn năm 2019 các huyện ven biển tỉnh Bến Tre theo 4 cấp độ tương ứng với giá trị EC: không nhiễm mặn $(0-4)$, nhẹ $(4-8)$, vừa $(8-16)$, rất mặn $(>16)$. Quy trình thực hiện được thể hiện bởi Hình 2.

\section{Kết Quả và Thảo Luận}

\subsection{Xác định phạm vi nghiên cứu}

Tỉnh Bến Tre nằm ở hạ lưu sông Mê Kông, có diện tích khoản $2.394 \mathrm{~km}^{2}$ với hệ thống sông rạch chằng chịt và tiếp giáp Biển Đông với chiều dài bờ biển gần $65 \mathrm{~km}$. Địa hình thấp với $90 \%$ diện tích đất tự nhiên của tỉnh có độ cao trung bình từ $1-2 \mathrm{~m}$ so với mực nước biển. Trong đó, các vùng đất thấp ven sông phân bố ở các huyện ven biển như huyện Bình Đại, Ba Tri và Thạnh Phú (độ cao dưới $1 \mathrm{~m}$ ) thường xuyên bị ngập khi triều cường (MFF, 2014) được chọn làm địa bàn nghiên cứu (Hình 3).

\subsection{Phân tích tương quan giữa giá trị $\mathrm{EC}$ và phản xạ phổ của ảnh Landsat}

Kết quả nghiên cứu của nhiều tác giả cho thấy, đặc trưng phổ của ảnh Landsat 8 với các thành phần muối ứng với các dải bước sóng khác nhau. Các loại muối sodium sulfate, halite, gypsum, calcium carbonate, sodium bicarbonate đều phản xạ mạnh (hơn $80 \%$ ) trong dải bước sóng từ 0,4 đến 1,4 $\mu \mathrm{m}$ (từ kênh khả kiến đến cận hồng ngoại) (Le \& ctv., 2019). Kết quả khảo sát từ bộ dữ liệu mẫu tại tỉnh Bến Tre thể hiện mối tương quan thực tế giữa giá trị độ mặn $\mathrm{EC}$ với giá trị phổ của ảnh Landsat 8 thể hiện như sau: kênh blue (Hình 4.a), green (Hình 4.b) và kênh red (Hình 4.c) có hệ số tương quan rất thấp $(\mathrm{r}<0,1)$, chứng tỏ không có mối tương quan với giá trị độ mặn EC. Trong khi đó, kênh NIR (Hình 4.d) có mối tương quan khá cao $(\mathrm{r}=0,791)$. Do đó, các giá trị pixel trên kênh NIR của ảnh Landsat 8 được sử dụng để phát triển mô hình giám sát độ mặn trong đất.

Bảng 2 thể hiện mô hình hồi quy với biến phụ 
Bảng 1. Công thức tính các chỉ số độ mặn dựa trên các kênh phổ ảnh Landsat 8 OLI

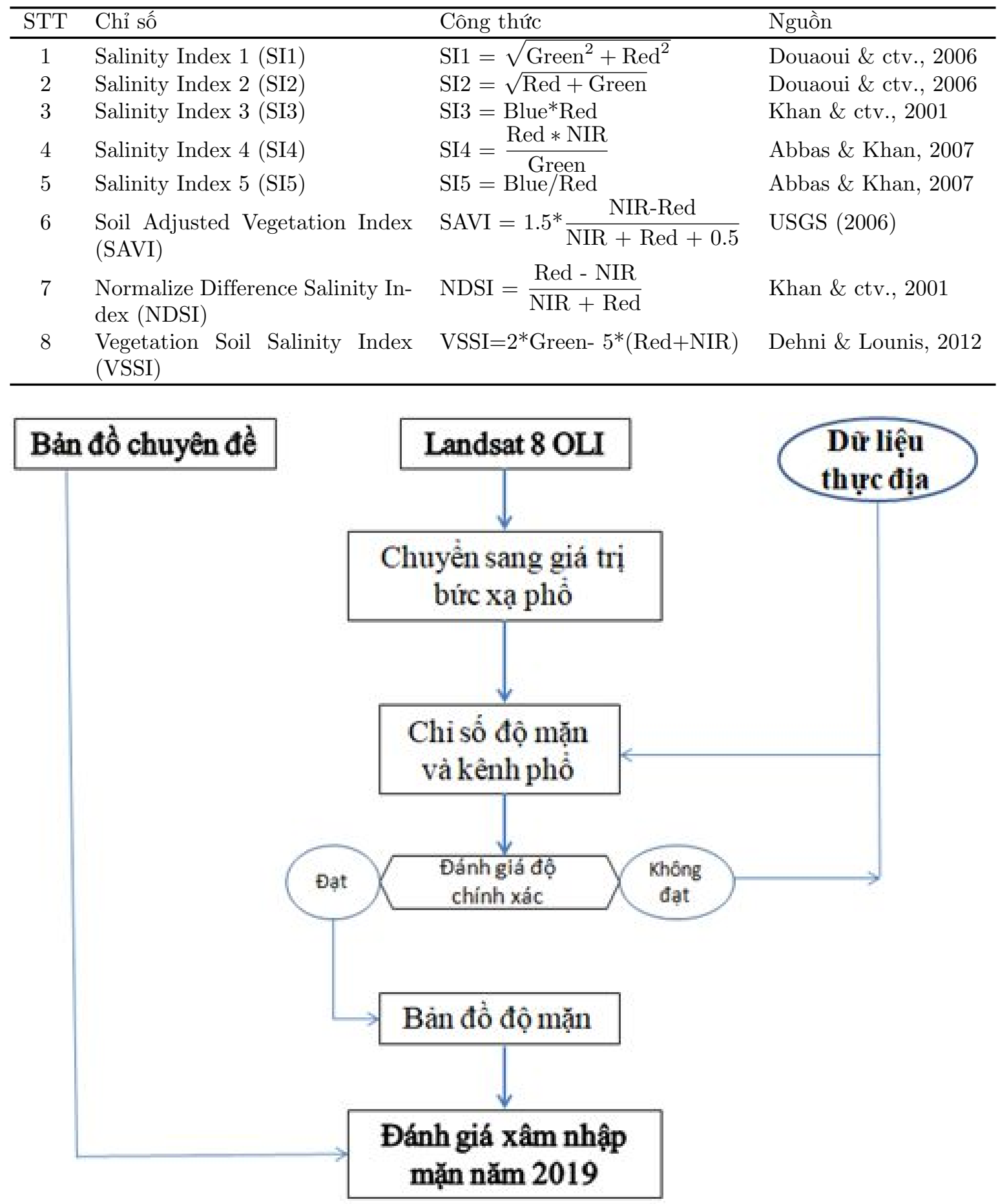

Hình 2. Quy trình đánh giá xâm nhập mặn năm 2019.

thuộc là EC (tại 28 điểm mẫu) và biến độc lập lần lượt là các kênh phổ red, green, blue. Mô hình giám sát độ mặn trong đất sử dụng kênh NIR có $\mathrm{r}=0,791$ được chọn trong nghiên cứu thể hiện bởi: $\mathrm{EC}=\mathrm{e}^{[\log (3.225)+3.820 * \mathrm{NIR}]}$ 
Bảng 2. Tương quan phản xạ phổ với giá trị độ dẫn điện (EC) trong thiết lập mô hình

\begin{tabular}{cclc}
\hline STT & Kênh phổ & Mô hình hồi quy & Tương quan $(\mathrm{r})$ \\
\hline 1 & Blue & $\mathrm{EC}=\mathrm{e}^{[\log (10.512)-5.223 * \text { Blue }]}$ & $-0,020$ \\
2 & Green & $\mathrm{EC}=\mathrm{e}^{[\log (6.362)-0.028 * \text { Green }]}$ & $-0,038$ \\
3 & Red & $\mathrm{EC}=\mathrm{e}^{[\log (7.340)-2.127 * \text { Red }]}$ & $-0,024$ \\
4 & NIR & $\mathrm{EC}=\mathrm{e}^{[\log (3.225)+3.820 * \mathrm{NIR}]}$ & 0,791 \\
\hline
\end{tabular}

\section{BĀN ĐOO HẢNH CHINNH \\ TISH BÉN TRE}

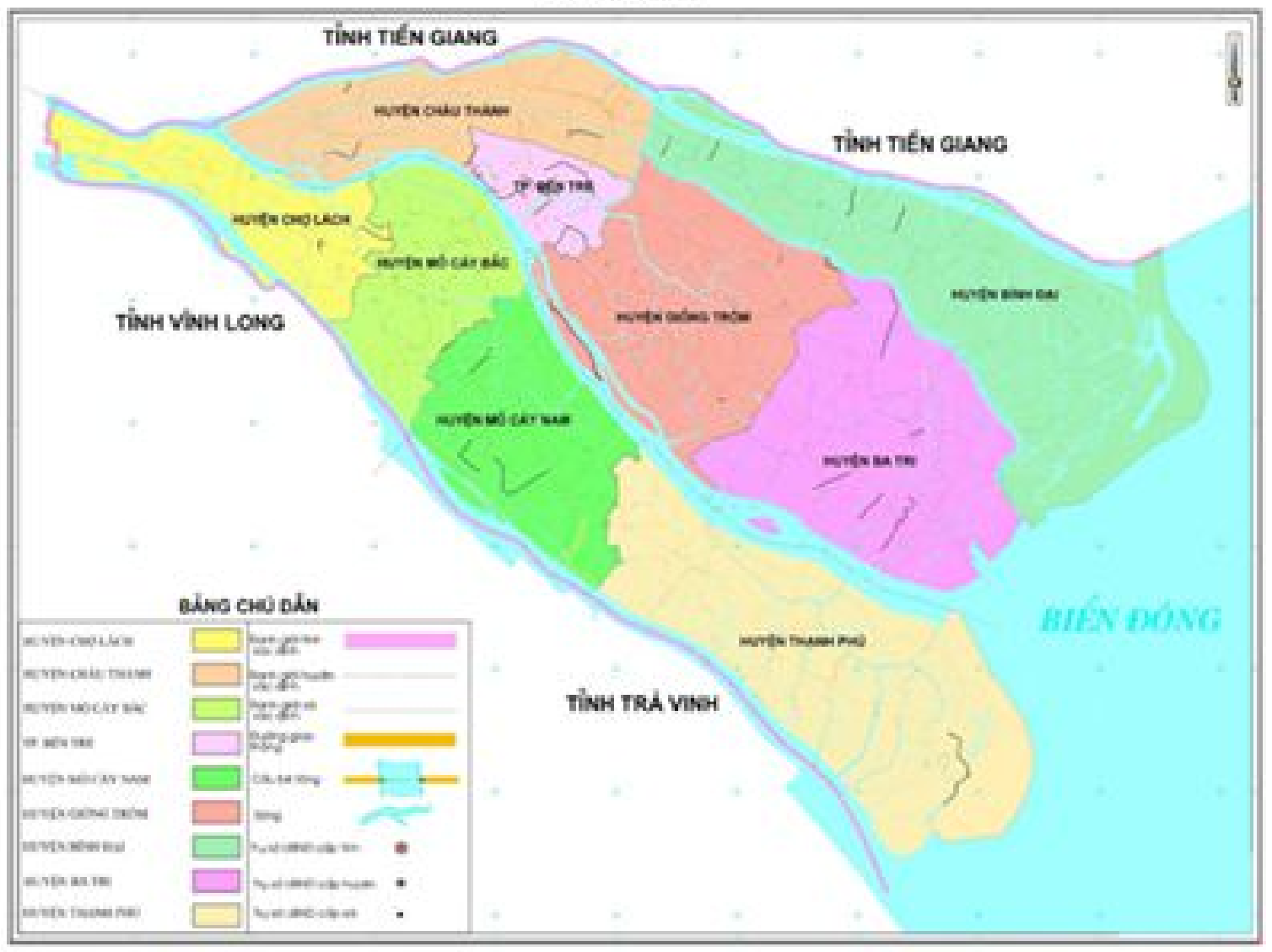

Hình 3. Vị trí vùng nghiên cứu.

Bảng 3. Tương quan giữa các chỉ số độ mặn và độ dẫn điện (EC)

\begin{tabular}{cclcc}
\hline STT & Chỉ số & Mô hình hồi quy & Tương quan $(\mathrm{r})$ & Độ lệch chuẩn của EC \\
\hline 1 & NDSI & $\mathrm{EC}=\mathrm{e}^{[\log (4,668)-1,155 * \text { NDSI }]}$ & 0,756 & 1,773 \\
2 & SAVI & $\mathrm{EC}=\mathrm{e}^{[\log (4,316)+2,081 * \mathrm{SAVI}]}$ & 0,740 & 1,637 \\
3 & VSSI & $\mathrm{EC}=\mathrm{e}^{[\log (2,868)-0,751 * \text { VSSI }]}$ & 0,703 & 1,855 \\
4 & $\mathrm{SI} 1$ & $\mathrm{EC}=\mathrm{e}^{[\log (8,477)-10,934 * \mathrm{SI} 1]}$ & $-0,27$ & 3,664 \\
5 & $\mathrm{SI} 2$ & $\mathrm{EC}=\mathrm{e}^{[\log (8,779)-19,798 * \mathrm{SI} 2]}$ & $-0,19$ & 3,629 \\
6 & $\mathrm{SI} 3$ & $\mathrm{EC}=\mathrm{e}^{[\log (7,456)-28,179 * \mathrm{SI} 3]}$ & $-0,037$ & 3,660 \\
7 & $\mathrm{SI} 4$ & $\mathrm{EC}=\mathrm{e}^{[\log (3,370)+4,825 * \mathrm{SI} 4]}$ & 0,587 & 2,313 \\
8 & $\mathrm{SI} 5$ & $\mathrm{EC}=\mathrm{e}^{[\log (3,187)+0,445 * \mathrm{SI} 5]}$ & 0,103 & 3,406 \\
\hline
\end{tabular}




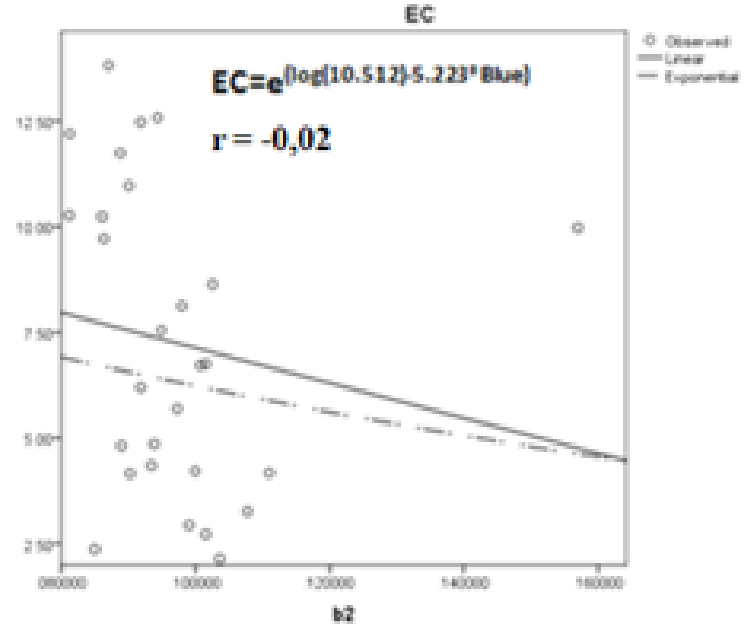

(a)

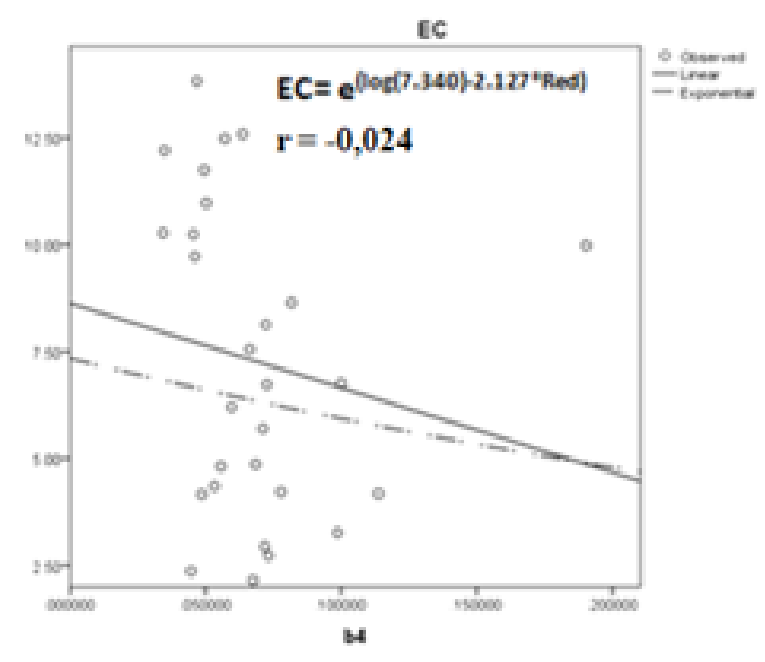

(c)

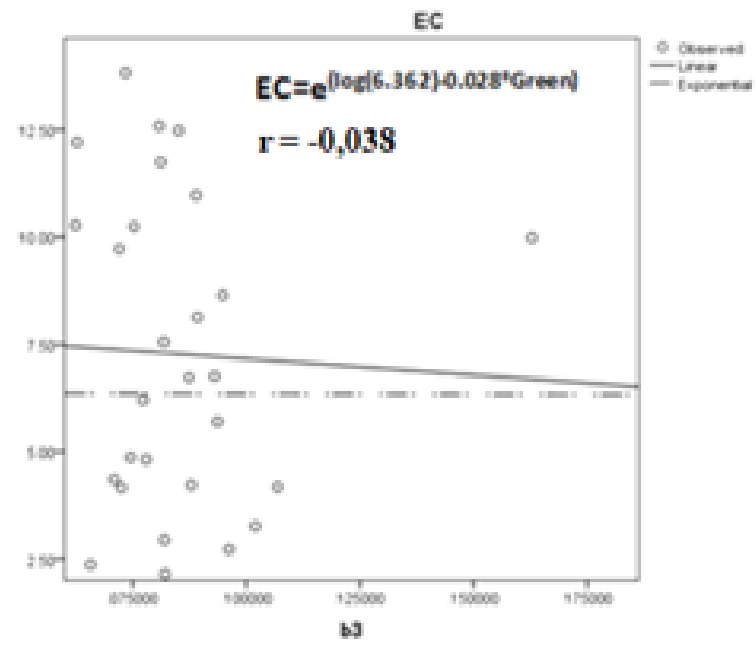

(b)

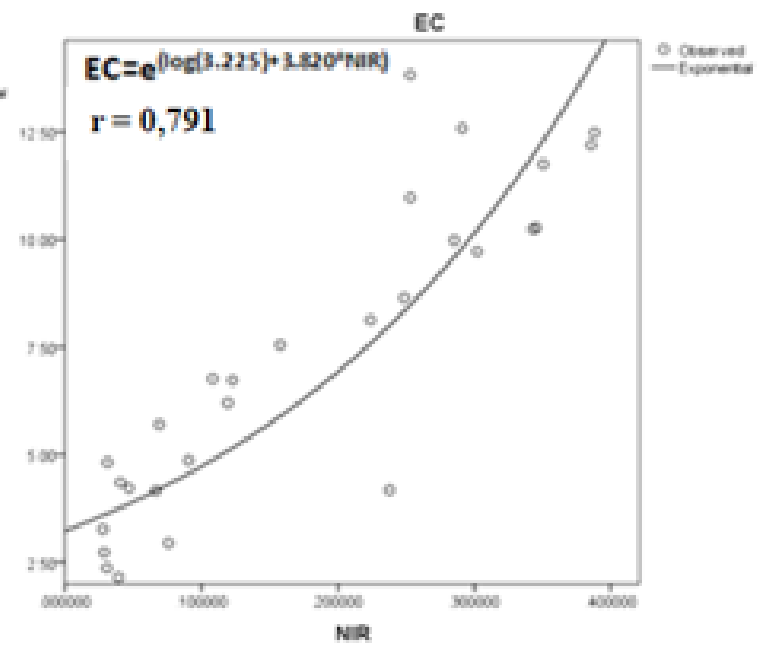

(d)

Hình 4. Đồ thị phân bố điểm mẫu tương ứng với các kênh phổ.

(a) - Kênh blue; (b) - Kênh green; (c) - Kênh red; (d) - Kênh NIR

\subsection{Sự tương quan giữa giá trị $\mathrm{EC}$ và các chỉ số độ mặn}

Các chỉ số độ mặn được trích xuất từ ảnh Landsat bao gồm 8 chỉ số: NDSI, SAVI, VSSI, SI1, SI2, SI3, SI4, SI5. Sử dụng phần mềm ENVI để tạo các ảnh chỉ số tương ứng và phần mềm SPSS trong phân tích tương quan giữa từng chỉ số với EC. Từ đó, chọn chỉ số có hệ số tương quan cao nhất.

Từ kết quả tính toán các chỉ số độ mặn tiến hành trích xuất các thông tin và phân tích tương quan với giá trị EC thực địa, kết quả thể hiện ở Bảng 3, Trong đó, 4 chỉ số có giá trị tương quan nhỏ hơn 0,50 đã bị loại (bao gồm SI1, SI2, SI3, SI5), Nghiên cứu cho thấy các chỉ số NDSI, SAVI, VSSI, SI4 có độ tương quan cao với EC, đặc biệt là chỉ số SAVI có độ lệch chuẩn nhỏ nhất $(1,637)$ tương ứng với độ tương quan $\mathrm{r}=0,740$, Do đó, việc sử dụng kênh phổ hồng ngoại gần (kênh NIR) rất khả thi trong thành lập bản đồ độ mặn của 


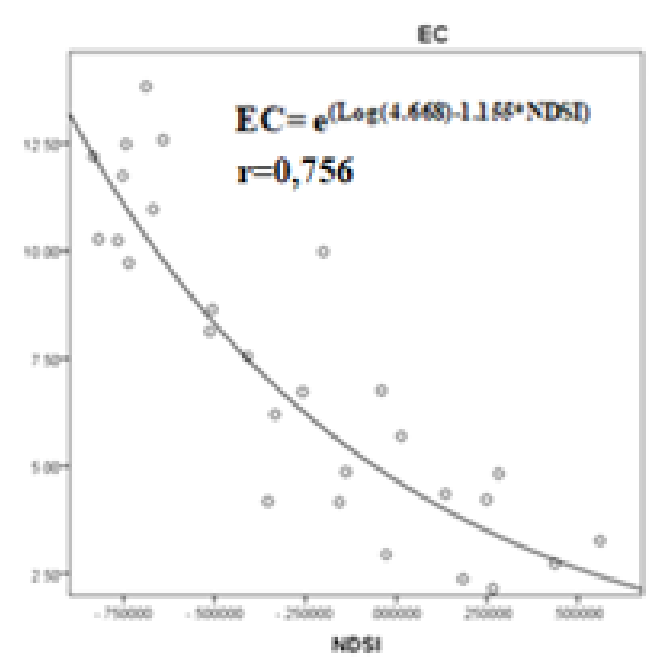

(a)

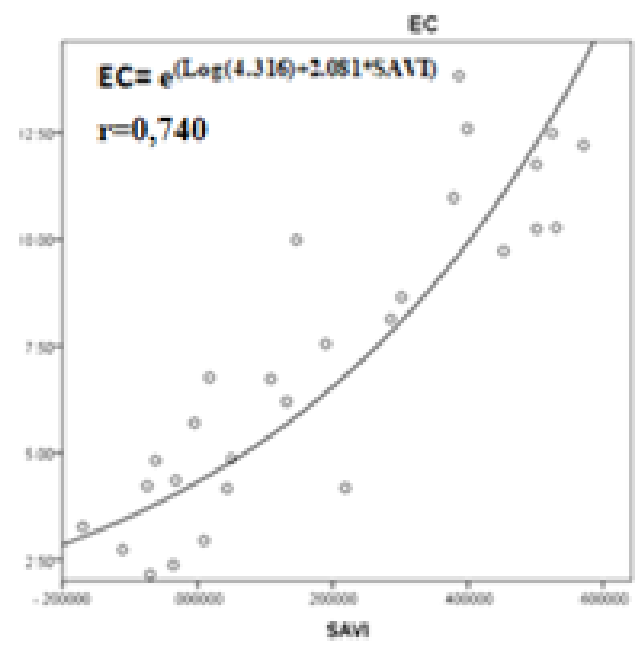

(c)

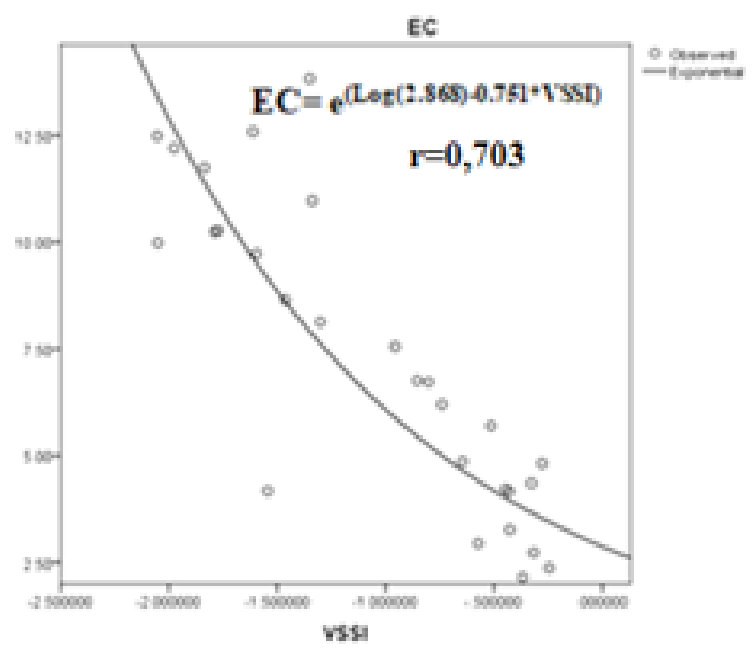

(b)

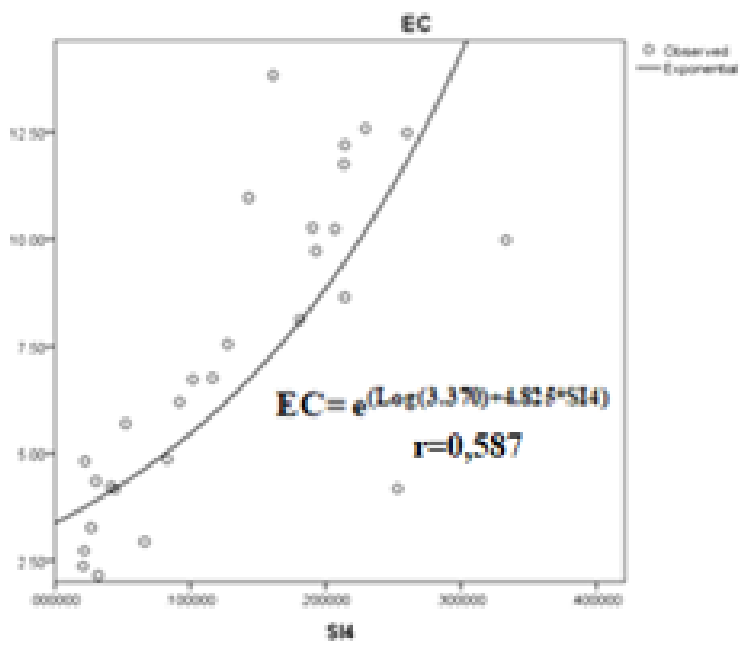

(d)

Hình 5. Đồ thị phân bố điểm mẫu tương ứng với các chi số độ mặn. (a) - NDSI; (b) - VSSI; (c) - SAVI; (d) - SI4

đất.

\subsection{Tạo bản đồ độ mặn của đất}

Sử dụng mô hình hồi quy để tính giá trị EC từ kênh NIR, từ đó tạo ảnh phân bố độ mặn đất EC cho vùng nghiên cứu. Hình 5 thể hiện bản đồ độ mặn được thành lập theo EC với 4 cấp độ tương ứng: 0 - 4 (không mặn); $4-8$ (mặn nhẹ); 8 - 16 (mặn vừa) và $\mathrm{EC}>16$ (mặn nặng).
Phân bố độ mặn trên địa bàn nghiên cứu cho thấy hầu hết huyện Thạnh Phú đều bị nhiễm mặn với độ mặn $\mathrm{EC}$ từ 4 - 16 xâm nhập sâu từ cửa biển vào đất liền khoảng $26 \mathrm{~km}$ (Hình 6 ). Xâm nhập mặn tại huyện Ba Tri theo hai hướng từ biển vào $5 \mathrm{~km}$ với độ mặn từ $8-16$ và hướng sông $\mathrm{Ba}$ Lai từ cửa $\mathrm{Ba}$ Lai vào $15 \mathrm{~km}$ và từ sông Ba Lai vào đất liền $1,5-2 \mathrm{~km}$, Huyện Bình Đại xâm nhập mặn theo hướng từ Cửa Đại và Cửa Ba Lai sâu $25 \mathrm{~km}$ vào đất liền. 


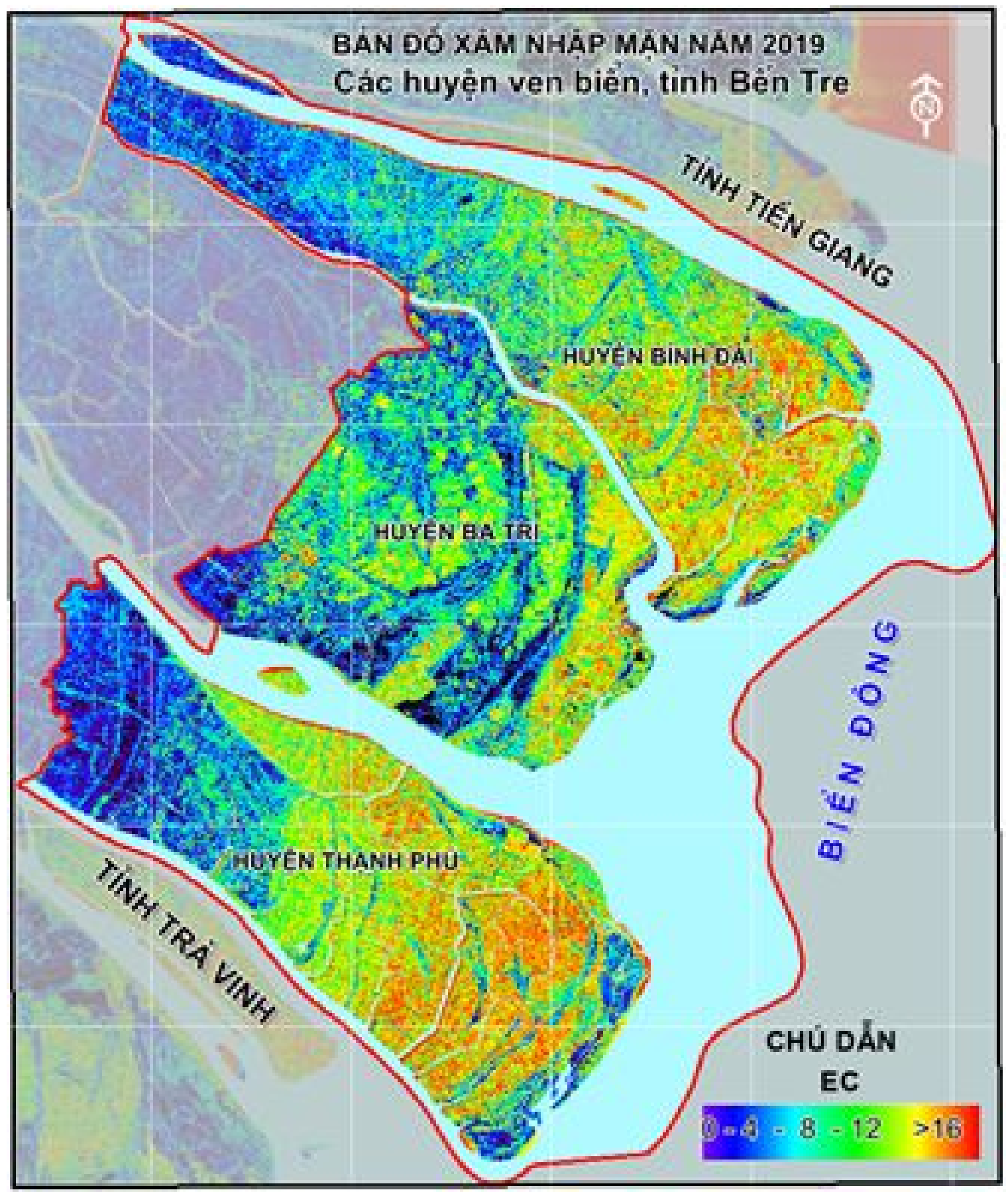

Hình 6. Bản đồ phân bố độ mặn của đất (EC).

Để đánh giá độ chính xác tiến hành phân tích sai lệch giữa các chỉ số độ mặn được trích xuất từ ảnh với các chỉ số EC thu được từ khảo sát thực tế (bộ dữ liệu mẫu).

Hình 7 cho thấy đồ thị phân bố độ mặn trên địa bàn nghiên cứu dựa vào việc trích xuất giá trị EC từ ảnh Landsat 8 OLI khá tương đồng với số liệu đo thực tế. Giải pháp đề xuất đã mở ra cơ sở khoa học trong thành lập bản đồ đánh giá độ mặn đất từ kênh NIR khá hiệu quả và tin cậy 


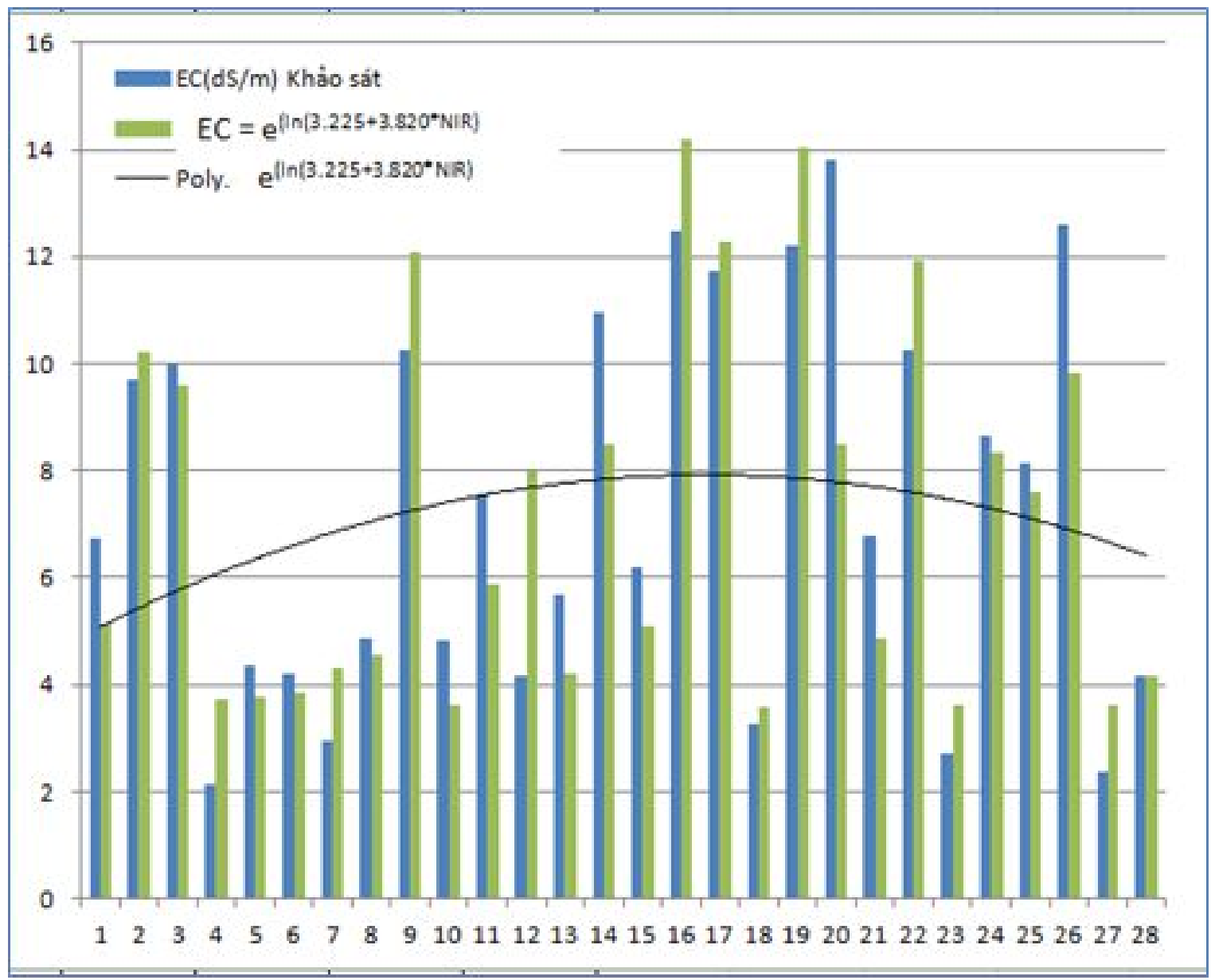

Hình 7. So sánh kết quả trích xuất giá trị độ dẫn điện (EC) từ mô hình và giá trị khảo sát.

cao $(\mathrm{r}=0,791)$. Ngoài ra, các kênh phổ khác của ảnh Landsat 8 còn ý nghĩa trong việc xác định các chỉ số độ mặn như chỉ số NDSI $(\mathrm{r}=0,756)$, SAVI $(\mathrm{r}=0,740)$, VSSI $(\mathrm{r}=0,703)$ và SI4 $(\mathrm{r}=$ $0,587)$.

\section{Kết Luận}

Bản đồ độ mặn đất $(\mathrm{EC})$ các huyện ven biển tỉnh Bến Tre được thành lập từ phương pháp viễn thám với ảnh Landsat 8 OLI kênh cận hồng ngoại (NIR) đã cho kết quả khả quan, đáng tin cậy (r $=0,791$ ) cho thấy tiềm năng lớn của ảnh Landsat trong đánh giá ảnh hưởng của xâm nhập mặn đến sản xuất nông nghiệp nói riêng và các hoạt động kinh tế - xã hội nói chung. Ảnh Landsat 8 OLI được truy cập dễ dàng, miễn phí và có thể được sử dụng để tính các chỉ số thông qua giá trị phản xạ các kênh phổ phục vụ phân tích tương quan với các chỉ số độ mặn đất và các chỉ số khác trong đất.

Kết quả nghiên cứu năm 2019 cho thấy hầu hết các huyện Thạnh Phú, Ba Tri và Bình Đại đều bị nhiễm mặn với giá trị $\mathrm{EC}$ từ 8 - 16. Độ mặn giảm dần theo hướng từ biển đông vào đất liền với khoảng cách từ 15 đến $25 \mathrm{~km}$. Giải pháp đề xuất đã mở ra hướng mới rất khả thi trong giám sát và đánh giá nhanh lan truyền mặn trong đất và thành lập bản đồ độ mặn đất cấp vùng và các tỉnh thuộc đồng bằng sông Cửu Long.

\section{Tài Liệu Tham Khảo (References)}

Abbas, A., \& Khan, S. (2007). Using remote sensing techniques for appraisal of irrigated soil salinity. In Oxley, L., and Kulasiri, D. (Eds.), MODSIM 2007 International Congress: Modelling and Simulation Society of Australia and New Zealand (2632-2638). Christchurch, New Zealand: 
Modelling and Simulation Society of Australia and New Zealand. Retrieved March 20, 2020, from https://researchoutput.csu.edu.au/en/publications/usingremote-sensing-techniques-for-appraisal-of-irrigatedsoil-s.

Ali, A. N., Mehdi, H., \& Abbas, F. (2012). Models to the identification of soil salinity: A case study from Garmsar Plain, Iran. International Journal of Environmental Physiology and Toxicology 9(1), 59-74.

Dehni, A., \& Lounis, M. (2012). Remote sensing techniques for salt affected soil mapping: Application to the oran region of Algeria. Procedia Engineering 33, 188-198.

Douaoui, E. K., Nicolas, H., \& Walter, C. (2006). Detecting salinity hazards within a semiarid context by means of combining soil and remote-sensing data. Geoderma, 134(1-2), 217-230.

Khan, N. M., Rastoskuev, V. V., Shalina, E. V., \& Sato, Y. (2001). Mapping salt-affected soils using remote sensing indicators - A simple approach with the use of GIS IDRISI. Proceedings of the 22 ${ }^{\text {nd }}$ Asian Conference on Remote Sensing (5-9). Singapore: Centre for Remote Imaging, Sensing and Processing (CRISP), National University of Singapore.

Le, T. V., Tran, V. T., \& Vo, V. N. (2019). Solution of integrating remote sensing and GIS in monitoring saline intrusion of Mekong river. Vietnam Journal of Science, Technology and Engineering 61(3), 22-26.

MFF (Mangroves for the Future). (2014). Assessment of land use changes using SPOT5 multi-time remote sensing images in project areas of Ben Tre and Tra Vinh provinces. Tra Vinh, Vietnam. Retrieved June 11, 2019 from https://www.mangrovesforthefuture.org/.
Neha, P. (2019). Use of Landsat satellite imagery to identify the salitization of soil due to brine spills in Northwestern North Dakota (Unpublished master's thesis). University of North Dakota, North Dakota, USA.

Nguyen, A. K., Liou, Y. A., Tran, H. P., Hoang, P. P., \& Nguyen, T. H. (2020). Soil salinity assessment by using near-infrared channel and vegetation soil salinity index derived from Landsat 8 OLI data: A case study in the Tra Vinh province, Mekong Delta, Vietnam. Retrieved March 15, 2020, from https://link.springer.com/article/10.1186/s40645019-0311-0\#article-info.

Shrestha, R. (2006). Relating soil electrical conductivity to remote sensing and other soil properties for assessing soil salinity in northeast Thailand. Land Degradation and Development 17(8), 677-689.

USGS (United States Geological Survey). (2006). Landsat surface reflectance-derived spectral indices. Retrieved March 15, 2020, from https://www.usgs.gov/corescience-systems/nli/landsat/landsat-soil-adjustedvegetation-index.

Watheq, S., Ebtihal, T. A. K., \& Sa'ad, R. Y. (2018). Using Landsat 8 OLI data to predict and mapping soil salinity for part of An-Najaf governorate. Ecology, Environment and Conservation Paper 24(2), 572-578. 